\title{
Young's Modulus of Single Crystalline Iron and Elastic Stiffness
}

\author{
Setsuo TAKAKI ${ }^{1)}$, Takuro Masumura ${ }^{1)^{*}}$ and Toshihiro TsuchiYAmA ${ }^{1,2)}$ \\ 1) Research Center for Steel, Kyushu University \\ 2) Department of Materials Science and Engineering, Kyushu University
}

Abstract: Elastic stiffness $c_{11}, c_{12}$ and $c_{44}$ are key parameters in the analysis of elastic deformation behaviors. In order to determine the values of these parameters, Young's modulus of single crystal; $E_{100}, E_{110}$ and $E_{111}$ are needed as well as Young' modulus Ep and Poisson's ratio $v$ in poly-crystal. In this paper, the values of Young's modulus in single crystalline iron are summarized and then elastic stiffness was estimated for pure iron under the conditions; $E_{\mathrm{p}}=208.2 \mathrm{GPa}$ and $v=0.291$ that are reliable values for isotropic poly-crystalline iron. As a result, it is found that Young's modulus of single crystalline iron should be as follows: $E_{100}=127.8 \mathrm{GPa}, E_{110}=214.3 \mathrm{GPa}, E_{111}=276.6 \mathrm{GPa}$. From these values, elastic stiffness of iron is calculated at $c_{11}=228.1 \mathrm{GPa}, c_{12}=135.0 \mathrm{GPa}, c_{44}=113.2 \mathrm{GPa}$. Diffraction Young's modulus of iron can be estimated on the basis of Kröner model by applying the values of elastic stiffness. It is also confirmed that the average value of diffraction Young's modulus agrees with the value of Young's modulus $E_{\mathrm{p}}(208.2 \mathrm{GPa}$ ) of ideal poly-crystalline iron.

Keywords: Young's modulus; diffraction Young's modulus; Poisson's ratio; single crystal; elastic stiffness; Kröner model; ideal poly-crystal; iron.

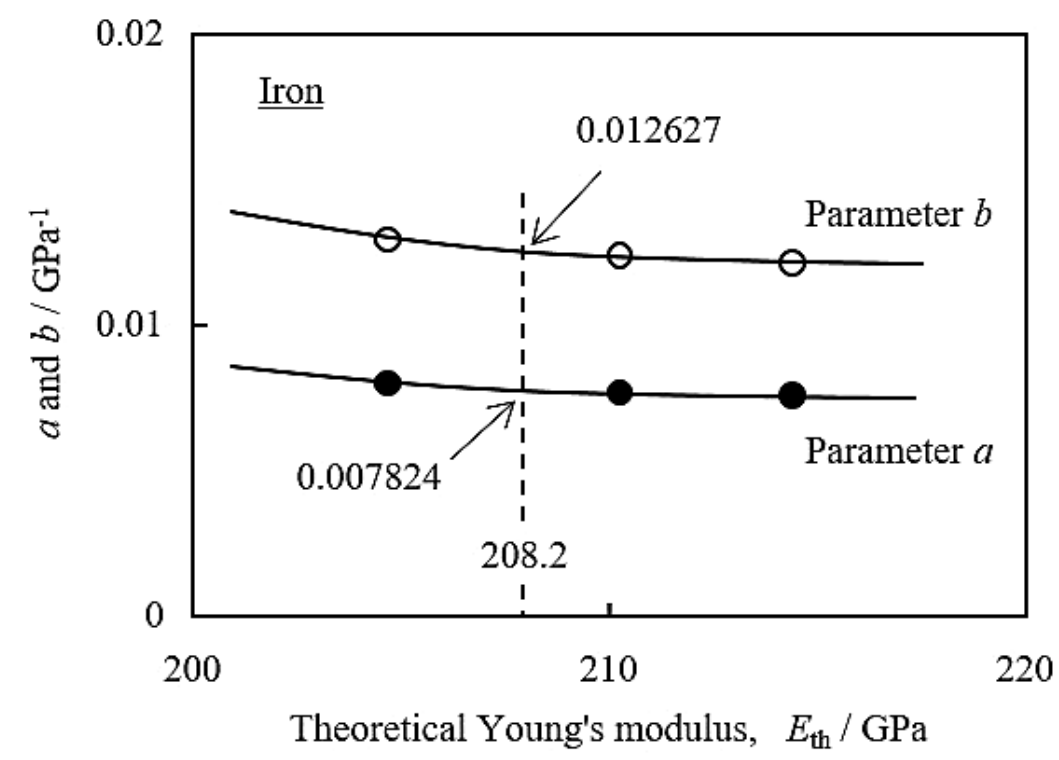

Received on Dec. 16, 2019 ; Accepted on Mar. 25, 2020

* Corresponding author. E-mail : masumura@zaiko.kyushu-u.ac.jp, Address : Kyushu University, 744 Motooka Nishi-ku Fukuoka 819-0395 


\section{単結晶鉄におけるヤング率と 弾性スティフネス}

高木 節雄 ${ }^{1)} \cdot$ 増村 拓朗 ${ }^{1) *} \cdot$ 土山 聡宏 ${ }^{1,2}$

Young's Modulus of Single Crystalline Iron and Elastic Stiffness

Setsuo TAKaki, Takuro Masumura and Toshihiro TsuchiYama

\section{1. 緒言}

金属材料における弾性スティフネス $c_{11}, c_{12}, c_{44}$ は, 弾性 変形に関連した様々な現象を解析するうえで重要なパラ メーターである。とくに，X線や中性子線による回折デー タを用いて転位解析を行う modified Williamson-Hall 法 ${ }^{1)}$ に おいては，転位のらせん成分を求めるうえでこれらのデー 夕は不可欠である ${ }^{2)}$ 。 $c_{11}, c_{12}, c_{44}$ の值を求めるための具体 的な方法については後述するが，これらの值を求めるため には, 多結晶体のヤング率とポアソン比に加えて, 単結晶 のヤング率 $\left(E_{100}, E_{110}, E_{111}\right)$ が分かっていなければならな い。凝固温度から室温まで相変態のない金属については比 較的容易に単結晶が得られ，これらの值を実験的に求める ことができるが, 凝固後の冷却中に固相変態が起こる鉄 については単結晶のヤング率を求めることは容易ではな い。実際には, 集合組織を有する材料の結晶方位分布とヤ ング率の関係に基づいて見積もる方法 ${ }^{3,4)}$ ，あるいは中性子 回折等の方法で得られた回折ヤング率から見積もる方法 ${ }^{5)}$ などがある。これらの方法で得られた単結晶のヤング率を Table 1 に示している。単結晶のヤング率は, $\langle 100\rangle,\langle 110\rangle$, 〈111〉の順に大きくなる傾向にあるが，それぞれの值につ いては研究者によってわずかに異なっている。

一方で，多結晶体のヤング率 $E_{\mathrm{p}}$ ならびにポアソン比 $v に$

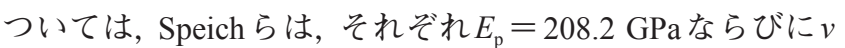
$=0.291$ という值を報告している ${ }^{6}$ 。彼らは, 結晶方位分布 が完全に等方的な鉄粉と多結晶鉄の回折強度を比較して 多結晶鉄の結晶方位分布が等方的であることを確認してお り，上記の值は理想的な多結晶鉄の弾性定数を示している

Table 1. Young's modulus $(\mathrm{GPa})$ in single crystalline iron.

\begin{tabular}{c|c|c|c}
\hline & Nagashima $^{3}$ & Kitagawa $^{4)}$ & Hutchings $^{5)}$ \\
\hline$E_{100}$ & 132.1 & 129.5 & 125.0 \\
$E_{110}$ & 220.8 & 216.5 & 210.5 \\
$E_{111}$ & 284.4 & 278.9 & 272.7 \\
\hline
\end{tabular}

と考えて良いであろう。本研究では, 多結晶鉄のヤング率 とポアソン比についてはこれらの值を採用し, 単結晶のヤ ング率の值が弾性スティフネス $\mathrm{c}_{\mathrm{ij}}$ に及ぼす影響を調査し た。さらに, 弾性スティフネス $\mathrm{c}_{\mathrm{ij}}$ の值を用いて理想多結晶 体のヤング率を理論的に求め, $E_{\mathrm{p}}=208.2 \mathrm{GPa}$ となるよう な正確な単結晶のヤング率を決定することで，これまでに 報告されたどのデータが最も妥当であるかを検討した。

\section{2. 単結晶鉄のヤング率と弾性スティフネスの関係}

結晶面が $\{\mathrm{hkl}\}$ の方位パラメーター る。

$$
\Gamma=\left(\mathrm{h}^{2} \mathrm{k}^{2}+\mathrm{k}^{2} \mathrm{l}^{2}+\mathrm{l}^{2} \mathrm{~h}^{2}\right) /\left(\mathrm{h}^{2}+\mathrm{k}^{2}+\mathrm{l}^{2}\right)^{2} \quad(0 \leqq \Gamma \leqq 1 / 3) \cdots(1)
$$

単結晶のヤング率 $E_{\mathrm{hkl}}$ の逆数と $\Gamma$ の間にはFig. 1 に示すよ うな直線関係があり, 両者の関係は一般的に次式で表され る。

$$
1 / E_{\mathrm{hkl}}\left[\mathrm{GPa}^{-1}\right]=a-b \times \Gamma
$$

弾性コンプライアンスを $s_{11}, s_{12}, s_{44}$ とした場合，パラメー ター $a$ と $b$ にいては次のような関係が成り立つ。

$$
\begin{aligned}
& s_{11}=a \\
& 2 s_{11}-2 s_{12}-s_{44}=b
\end{aligned}
$$

また，等方多結晶体の圧縮率 $\kappa$ にいては，ヤング率 $E$ と

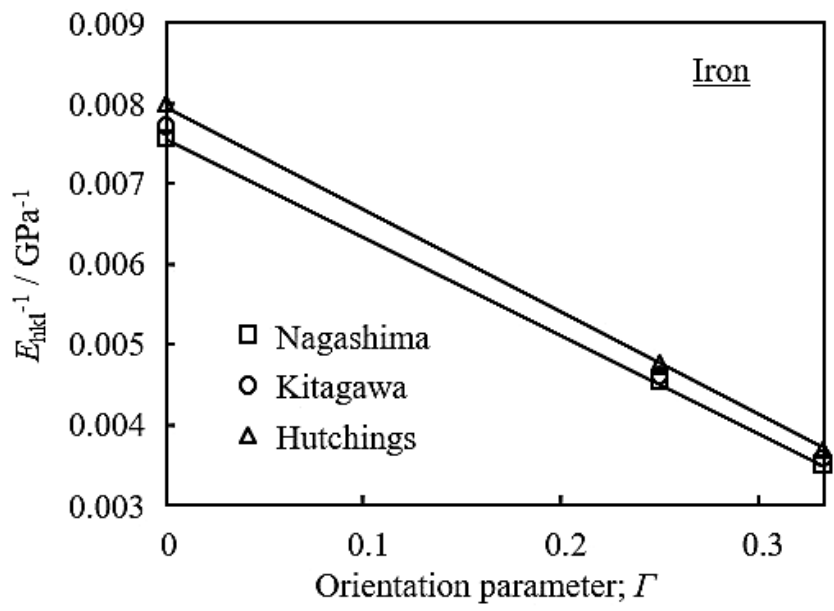

Fig. 1. Relation between orientation parameter $\Gamma$ and the reciprocal of Young's modulus $E_{\mathrm{hkl}}$ in single crystalline iron. 
ポアソン比 $v$ の值が分かっていれば次式で求めることがで きる。本研究では，ポアソン比はSpeichらが報告したv= 0.291 を用いた。Eについては，3章で述べる直接平均化法 で求めた等方多結晶体のヤング率 $E_{\mathrm{th}}$ を用いた。

$$
\kappa=3(1-2 v) / E
$$

また， $\kappa$ と $s_{11}, s_{12}$ の間には次式が成立する。

$$
\kappa=3\left(s_{11}+2 s_{12}\right)
$$

したがって，式 (3)，(4)，(6) の連立方程式を解くことに よって $s_{11}, s_{12} ， s_{44}$ の值がすべて求められ，これらの值を用 いて次式により弾性スティフネス $c_{11}, c_{12}, c_{44}$ を決定でき る。

$$
\begin{aligned}
& c_{11}=\left(s_{11}+s_{12}\right) /\left(s_{11}-s_{12}\right) /\left(s_{11}+2 s_{12}\right) \\
& c_{12}=-s_{12} /\left(s_{11}-s_{12}\right) /\left(s_{11}+2 s_{12}\right) . \\
& c_{44}=1 / s_{44}
\end{aligned}
$$

Fig.1のデータから得られるパラメーター $a$ と $b$ 小らび に以上のようにして得られた弾性スティフネス $c_{11}, c_{12}, c_{44}$ の值をまとめて Table 2 に示す。当然の結果ではあるが, 研 究者によって単結晶のヤング率の值が異なっているために 弾性スティフネスにも差が生じている。

\section{3. 理想多結晶体モデルに基づいた ヤング率の見積もり}

結晶方位が完全に等方的な多結晶体 (理想多結晶体) を 作製することは容易ではないが，理想的なモデルを構築す ることは可能である。本研究では, 球面座標における分割 面積が等しくなるように2040点の結晶方位べクトルを均 等に配置して理想多結晶体モデルとした ${ }^{7)} 。 2040$ 点の結晶 粒についてはすべて方位パラメーターГの值は分かってお り，その平均值は，結晶方位が完全に等方的な多結晶体の $\Gamma$ 值 $(0.200)^{8)}$ に一致することを確認している。本稿では, 多結晶体における個々の物性值を直接平均化して多結晶体 の物性值を求める方法を直接平均化法ということにする。

Table 2. Values of parameter $a$ and $b\left(\mathrm{GPa}^{-1}\right)$ and elastic stiffness $c_{\mathrm{ij}}(\mathrm{GPa})$ in iron.

\begin{tabular}{c|c|c|c|c|c}
\hline & $a$ & $b$ & $c_{11}$ & $c_{12}$ & $c_{44}$ \\
\hline Nagashima & 0.00757 & 0.01215 & 235.2 & 138.9 & 116.3 \\
Kitagawa & 0.00772 & 0.01240 & 230.6 & 136.2 & 114.1 \\
Hutchings & 0.00800 & 0.01300 & 223.9 & 132.9 & 111.6
\end{tabular}

ポアソン比に関して, 多結晶鉄の回折ポアソン比昼を用い て直接平均化法で得た值は 0.292 であり ${ }^{7)}$, この值は Speich らが実験的に求めた $0.291^{6)}$ にほぼ一致している。この結果 は, Speichらが使用した多結晶鉄の結晶方位分布がほぼ等 方的であったことを示唆している。

多結晶体のヤング率についても, 多結晶体を構成する各 結晶粒の回折ヤング率 $E_{\mathrm{hkl}}^{*}$ が分かっていれば直接平均化 法により理論的な值 $E_{\mathrm{th}}$ が求められる ${ }^{7)}$ 。弾性スティフネ ス $c_{11}, c_{12}, c_{44}$ の值が既知の材料については, Kröner 法 ${ }^{8)} に$ よって結晶面 $\{\mathrm{hkl}\}$ に対応した $E_{\mathrm{hkl}}^{*}$ の值を求めることが可 能であり, 方位パラメーター $\Gamma$ と $E_{\mathrm{hk} 1}^{*}$ の関係は一般的に次 式で表される。

$$
1 / E_{\mathrm{hkl}}^{*}=a^{*}-b^{*} \times \Gamma
$$

Kröner 法 ${ }^{8)}$ につては広く知られているためここでは具体 的な解析法は省略するが，Table 2 に示した弾性スティフネ スの值を用いて得られた $a^{*}$ と $b^{*}$ の值ならびに直接平均化 法で得られた $E_{\mathrm{th}}$ の值を Table 3 に示す。ここで注意すべき 点は，式（5）において $E$ の值を入力しなければならないということである。本研 究では, $E$ に様々な值を代入して上記の計算を繰り返し, $E=E_{\mathrm{th}}$ となる条件を見出した。Kitagawaのデータ ${ }^{4)}$ を用 いた場合に208.2 GPaに最も近い值 $(210.2 \mathrm{GPa})$ が得られ ており,この結果は, 単結晶鉄のヤング率としてKitagawa が提示した值が最も妥当なことを示している。ここでは,

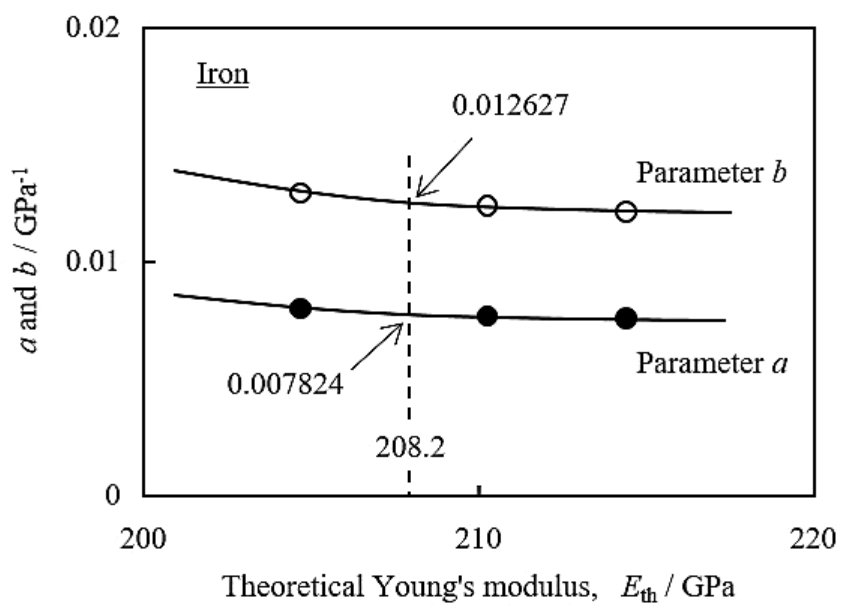

Fig. 2. Relation between theoretically obtained Young's modulus $E_{\text {th }}$ and the values of parameter $a$ and $b$ in Eq.2.

Table 3. Values of parameter $a^{*}$ and $b^{*}\left(\mathrm{GPa}^{-1}\right)$ and theoretically obtained Young's modulus $E_{\text {th }}(\mathrm{GPa})$ in iron.

\begin{tabular}{c|c|c|c}
\hline & $a^{*}$ & $b^{*}$ & $E_{\text {th }}$ \\
\hline Nagashima & 0.005694 & 0.004966 & 214.4 \\
Kitagawa & 0.005808 & 0.005067 & 210.2 \\
Hutchings & 0.005983 & 0.005287 & 204.7 \\
\hline
\end{tabular}


さらに正確な值を求めるために，理想多結晶鉄のヤング 率を208.2 GPa として，単結晶のヤング率を見積もった。 Fig.2 には Table 2 およびTable 3 に示した $a$ および $b$ と $E_{\mathrm{th}}$ の 関係を示している。この眓より, $208.2 \mathrm{GPa}$ のヤン゙率に 対応するパラメーター $a$ と $b$ 值を読み取ると，それぞれ 0.007824 と 0.012627 であり, 最終的に $E_{100}=127.8 \mathrm{GPa}, E_{110}$ $=214.3 \mathrm{GPa}, E_{111}=276.6 \mathrm{GPa}$ という結果が得られた。これ らの值を用いて再度弾性スティフネスの值を計算すると， $c_{11}=228.1 \mathrm{GPa}, c_{12}=135.0 \mathrm{GPa}, c_{44}=113.2 \mathrm{GPa}$ という結 果が得られた。

\section{4. まとめ}

理想多結晶鉄のヤング率を $208.2 \mathrm{GPa}$ ，ポアソン比を 0.291 として単結晶鉄のヤング率を求めた結果, $E_{100}=$ $127.8 \mathrm{GPa}, E_{110}=214.3 \mathrm{GPa}, E_{111}=276.6 \mathrm{GPa}$ という值が得 られた。これらの值を用いて弾性スティフネスの值を計算 すると, $c_{11}=228.1 \mathrm{GPa}, c_{12}=135.0 \mathrm{GPa}, c_{44}=113.2 \mathrm{GPa}$ と いう結果が得られた。

\section{謝辞}

本研究は, JSPS科研費JP15H05768の支援を受けて行わ れたものである。な打, 研究の一部は, 日本鉄鋼協会「鉄鋼 のミクロ組織要素と特性の量子線解析研究会」のもとで実 施された。

\section{文献}

1 ) T.Ungár and A.Borbély: Appl. Phys. Lett., 69(1996), 3173.

2 ) T.Ungár, I.Dragomir, Á.Révész and A.Borbély: J. Appl. Crystallogr., 32(1999), 992.

3 ) 長島晋一: 多結晶の結晶方位分布の制御と材料特性, 日本金 属学会, 仙台, (1992), 41.

4 ) H.Kitagawa: J. Soc. Mater. Sci., Jpn., 29(1980), 691 (in Japanese).

5 ) M.T.Hutchings, P.J.Withers, T.M.Holden and T.Lorentzen: Introduction to the characterization of residual stress by neutron diffraction, CRC Press, Taylor \& Francis, Oxford, (2005), 229.

6 ) G.R.Speich, A.J.Schwoeble and W.C.Leslie: Metall. Trans., 3(1972), 2031.

7 ) S.Takaki, T.Masumura and T.Tsuchiyama: J. Soc. Mater. Sci., Jpn., 69(2020), 657 (in Japanese).

8 ) 田中啓介, 鈴木賢治, 秋庭義明 : 残留応力の $\mathrm{X}$ 線解析, 養賢堂, 東京, (2006), 275. 